\title{
Blepharoplasty and Eyelid Resurfacing: Blepharolaser
}

\author{
Jorge Schwember ${ }^{1, *}$, Gerardo Schwember², Mauricio Rivas ${ }^{3}$, Luisa Madrid ${ }^{1}$, and Ariel Kurtzig ${ }^{4}$ \\ ${ }^{1}$ Centro Laser, La Serena, Chile \\ ${ }^{2}$ Clínica Alemana, Santiago, Chile \\ ${ }^{3}$ Clínica Valle Norte, Ovalle, Chile \\ ${ }^{4}$ Universidad de Chile, Escuela de Medicina, Santiago, Chile
}

*Corresponding author: Schwember J, Centro Laser, La Serena, Chile; E-mail: jschwember@centrolaserlaserena.cl

Received: 19 Jan, 2021 | Accepted: 25 Jan, 2021 | Published: 02 Feb, 2021

Citation: Schwember J, Schwember G, Rivas M, Madrid L, Kurtzig A (2021) Blepharoplasty and Eyelid Resurfacing: Blepharolaser. J Clin Cosmet Dermatol 5(1): dx.doi.org/10.16966/2576-2826.161

Copyright: (C2021 Schwember J, et al. This is an open-access article distributed under the terms of the Creative Commons Attribution License, which permits unrestricted use, distribution, and reproduction in any medium, provided the original author and source are credited.

\begin{abstract}
Blepharoplasty is a demanding cosmetic surgery. When surgery is being considered, ophthalmic tests, such as visual acuity, eye pressure and tear film, are important. Additional treatments have been incorporated to the traditional surgical procedure to improve periorbital skin of which the most accepted is laser resurfacing. In this study, the authors report their experience with 63 patients operated on between 2014 and 2020 and propose an algorithm to apply Er:YAG laser to the eyelid skin.
\end{abstract}

Keywords: Dermatochalasis; Blepharochalasis; Eyelid surgery; Laser resurfacing; Transconjunctival Blepharoplasty; Eyelid skin thickness

\section{Introduction}

The number of patients undergoing blepharoplasty has been rapidly growing and is now one of the most frequent cosmetic surgical procedures [1-3]. The first written evidence of excision of the upper eyelid skin is found in the book De Medicina of Aulus Cornelius Celsus $25 \mathrm{AD}$ [4]. Since then, the technique has experienced many changes and improvements [5-7] one of the latest has been applying laser to the periorbital skin $[8,9]$. The senior author, who received his training for laser eyelid resurfacing during a Sciton summit in 2013, was advised at that time to apply no more than 90 microns for eyelid ablation. With forty-five years in oculoplastic surgery and seven working with skin Er:YAG laser, the author has increased the earlier guidelines regarding depth of ablation. It is essential to consider Fitzpatrick's skin classification [10] and skin thickness when adding laser resurfacing to a blepharoplasty. This article reviews the authors' experience and provides an algorithm for laser eyelid resurfacing.

\section{Methods}

This was a retrospective analysis of 63 blepharoplasty patients (49 to 84 years old), performed by one surgeon (J.S.) between 2014 and 2020. This report adhered to the ethical principles outlined in the declaration of Helsinki and approved by the ethical review board, all research was HIPAA compliant, and a signed informed consent was obtained from each patient participating and/or photographed and is on file. Selection criteria were based on overall general health, predisposition to hypertrophic scars or keloids, healthy periorbital skin and only included non-smokers. A routine ophthalmic examination was carried out including a tear film evaluation. V and VI Fitzpatrick skin classification types were excluded. Written consent was obtained for the surgical procedure and to allow pre- and post-surgical photos for recording and publishing. These photos were analyzed by the patient and the authors at the three-month final check-up.

In sixteen patients, the treatment was extended to a complete laser facial rejuvenation, their facial skin condition being documented by a Visia ${ }^{\circ}$ Skin Analysis System (Figures 1 and 2). In these patients, $200 \mathrm{mg}$ of cefpodoxime, a broad spectrum antibiotic, was prescribed for 5 days. In patients with a history of herpes, $400 \mathrm{mgs}$ of acyclovir every 12 hours was prescribed for 7 days. Both medications began two days before surgery. Seven days prior to surgery, patients were advised to take $1 \mathrm{gr}$ of ascorbic acid daily to minimize bleeding [11]. Blepharoplasty patients, not receiving laser facial rejuvenation, were only prescribed ascorbic acid. Fitzpatrick III and IV patients received topical depigmenting cream (Triluma') four weeks before surgery which was then suspended seven days before the operation [12].

All patients were from the private practice of the senior author (J.S.), and all surgeries were performed in his office under local anesthesia plus mild sedation on an outpatient basis. An anesthesiologist attended the patients receiving facial rejuvenation.

The surgical procedure was performed first. Regarding the lower lids, this cohort considered only the transconjunctival blepharoplasty approach. Er:YAG laser $2940 \mathrm{~nm}$ provided by a Joule unit of Sciton was applied as a final step. At the end of the procedure ice packs soaked in an iodine solution were applied for one hour. The patient was discharged with a thin layer of petroleum jelly cream on the treated areas. Each patient received oral and written post-care instructions and was encouraged to contact the surgeon or staff at any time. Home care included resting in an upright position, the use of a handheld fan 

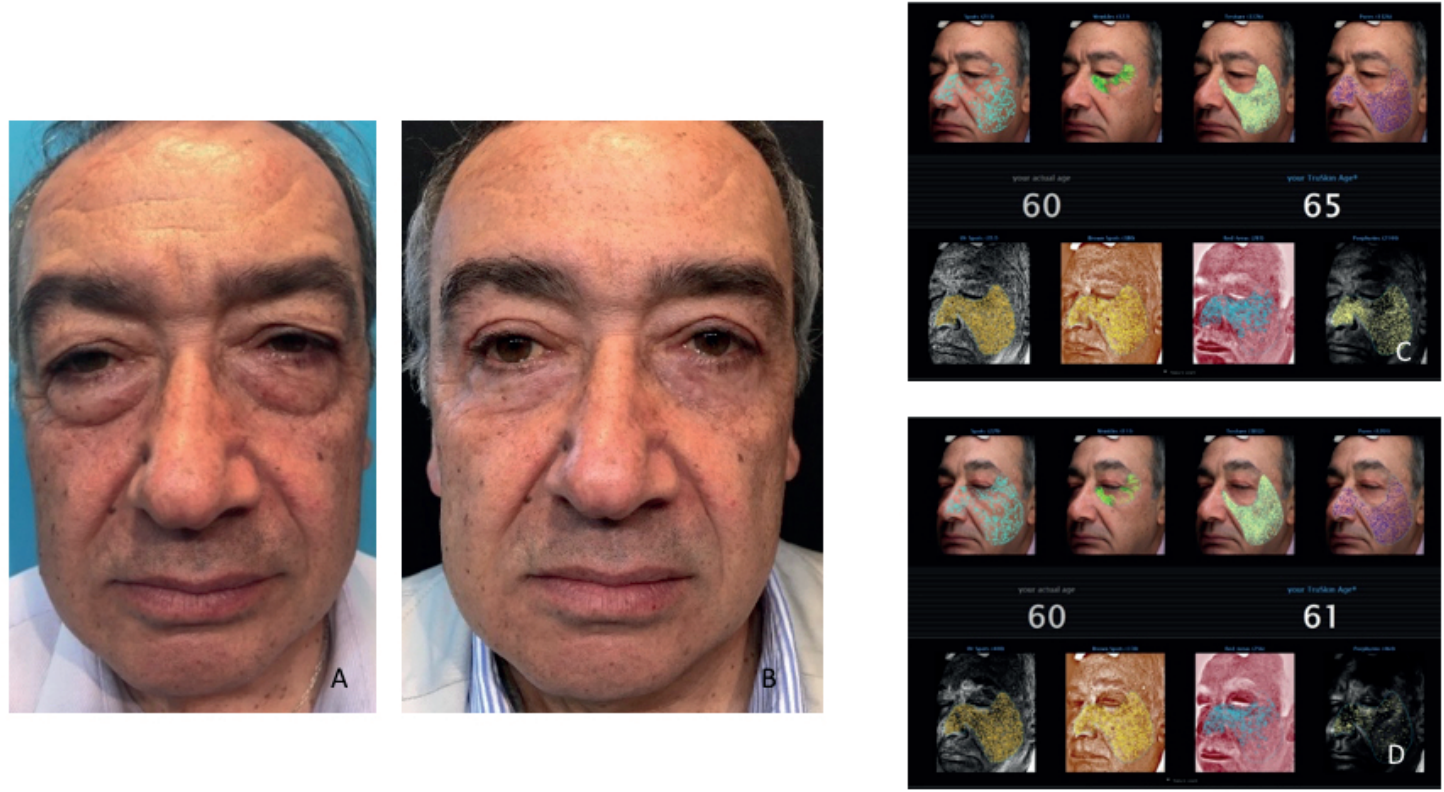

Figure 1 A: preoperative, B: postoperative at 4 months. The facial ablation was a microlaser peeling of $30 \mu \mathrm{m}$ due to his IV Fitzpatrick skin. C: Preoperative facial scan. Actual age: 60 years old, apparent age: 65 years old. D: Postoperative at 4 months. Actual age: 60 years old, apparent age: 61 years old.
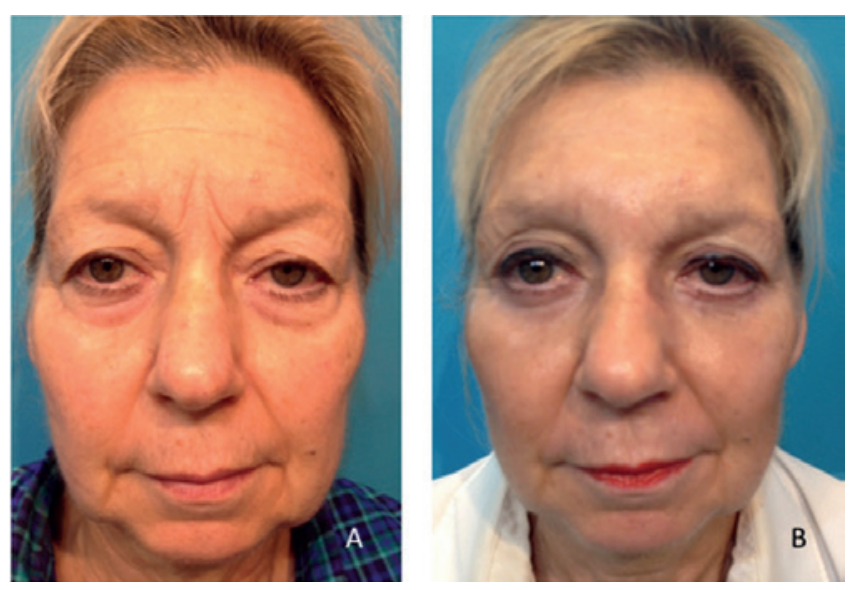

Figure 2 A: preoperative, B: postoperative at 3 months. Facial laser considered 40-300 $\mu \mathrm{m}$ of conventional ablative resurfacing and 75-400 $\mu \mathrm{m}$ of fractional ablative resurfacing.

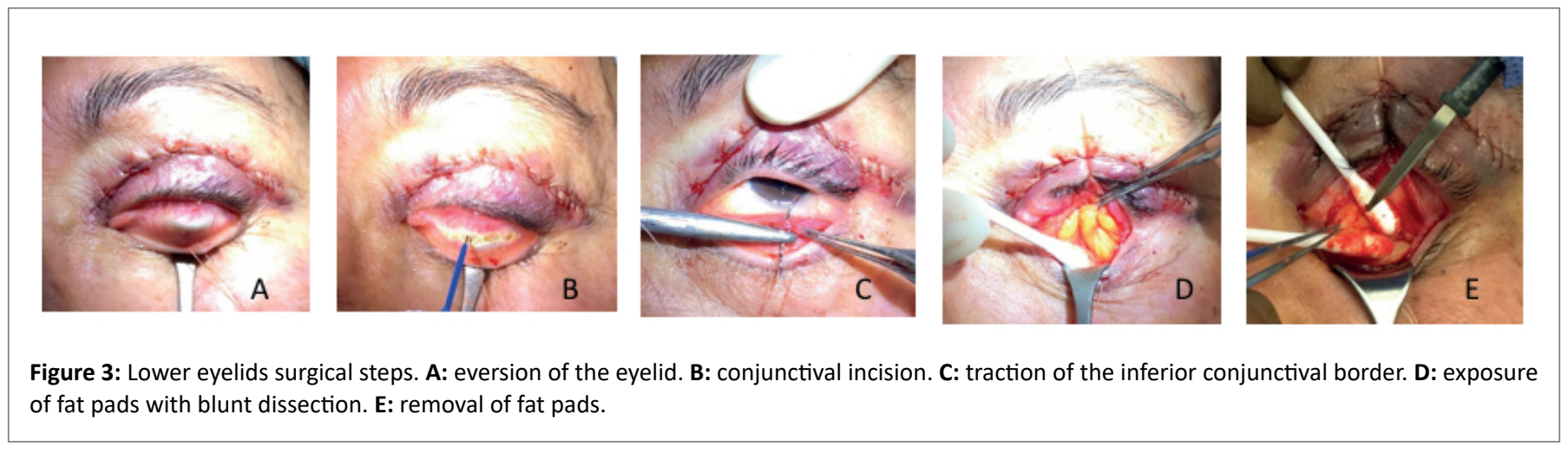




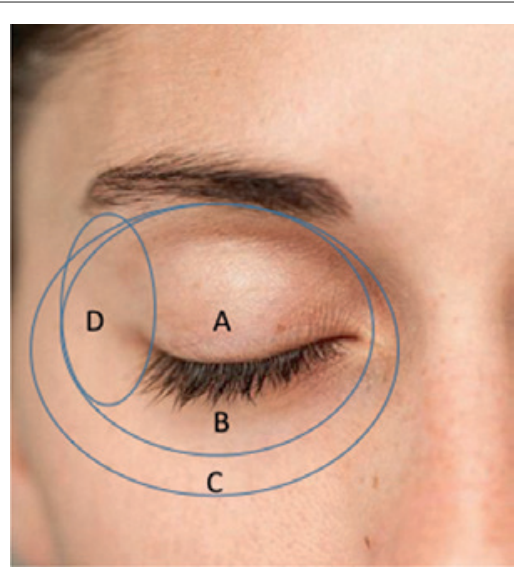

Figure 4: Different periorbital zones for laser treatment. A: upper eyelid, B: lower eyelid, C: feathering, D: lateral canthal.
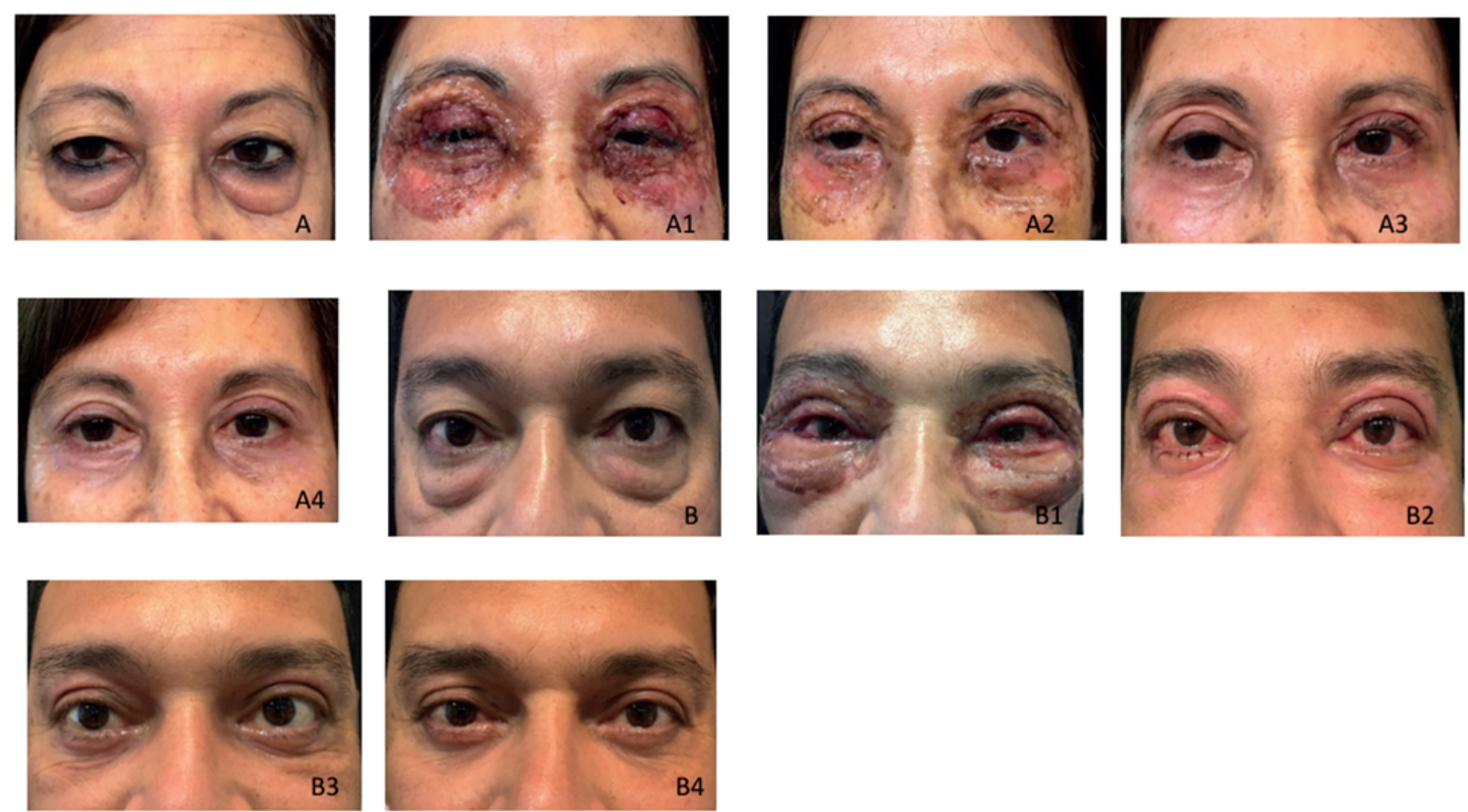

Figure 5: Two patients and their postoperative evolution. A: preoperative; $A 1, A 2, A 3:$ at 3,7,18 days respectively. A4: at 4 months. B: preoperative; B1, B2, B3: at 1, 7, 22 days respectively. B4: at 3 months.

to cool the affected area on the first day, $200 \mathrm{mg}$ of celecoxib every 12 hours if necessary, and petroleum jelly cream every 4 hours for 5 days. Topical antibiotic and steroid eye drops were instilled for 2 weeks in decreasing doses. To sleep, a shower cap with a hole cut out for the nose was recommended to protect the face for 5 days. If there was intense eyelid edema furosemide $40 \mathrm{mg}$ twice a day was prescribed. The first checkup was scheduled at two days with following check-ups scheduled at 5, 10 and 30 days, and the last at 3 months.

\section{Surgical Technique}

Topical proparacaine hydrochloride $0.5 \%$ eye drops were instilled first. The entire face was cleansed with $96^{\circ}$ alcohol and then draped. No oxygen mask was used to avoid laser facial burns. The operations were performed under local anesthesia using regional blocks according to Zide MB, et al. [13]. In the lower eyelids, a subconjunctival and a peribulbar bolus of $0.5 \mathrm{cc}$ were added. The anesthetic solution was lidocaine $2 \%$ with epinephrine 1:100,000 plus sodium bicarbonate $8.4 \%$ in a $1: 10$ dilution. For light oral sedation, 5 to $10 \mathrm{mg}$ of Valium was given. In those patients undergoing total facial rejuvenation, an anesthesiologist determined the guidelines for sedation.

Upper eyelids: The recommendations given by CC McCord CD, et al. [14] were followed with two modifications. The first was the infiltration of anesthesia with a $27 \mathrm{G}$ blunt cannula under the skin orbicularis muscle of the ellipse to be removed. During the following ten-minute waiting period, equipment was set up and an instrument checklist performed. The second innovation is the placement of a 
running suture of nylon 6/0 with a loop knot at both ends; every two stitches, the levator aponeurosis is included. This modality facilitates the removal of stitches at 5 or 6 days.

Lower eyelids: A traction suture of plain catgut $5 / 0$ was anchored horizontally at the margin of the middle third of the lid (Traction 1). A Desmarres retractor and the suture everted the eyelid. A pinpoint electrode (Hyfrecator ${ }^{\circledR}$ ) opened the conjunctiva $1.5 \mathrm{~cm}$ length between the inferior border of the tarsus and the fornix. Another traction suture of plain catgut $5 / 0$ was placed in the center of the inferior conjunctival border from anterior to posterior, keeping the needle threaded. At the end of the procedure, this suture would be the single union of the excised conjunctiva with a buried knot (Traction 2). The Desmarres retractor was relocated pulling the superior conjunctival border down. Blunt dissection was performed exposing the fat pads which were removed directly with the electrosurgical unit protecting the surrounding tissues with sterile cotton tip applicators (Figure 3). Bipolar electrohemostasis of bleeding points was carried out. The conjunctiva is closed only with the Traction 2 suture of catgut 5/0 with a buried knot and then traction 1 was removed. Antibiotic and steroid ophthalmic ointment was applied.

Eyelid laser resurfacing: Topical proparacaine hydrochloride $0.5 \%$ eye drops were instilled again. Metal scleral shields (Katena) were placed. The outer border of the laser ablation was marked with a white paper correction pen and the pigmented lesions as well (Faber-Castell ${ }^{\circ}$ cannot be erased with alcohol).

Laser depth was programmed according to our algorithm (Figure 4 and Table 1). Laser is applied in Zones A, B and C with conventional ablative resurfacing (Contour TRL') overlap set at $50 \%$ in two passes. The first pass was vertical without coagulation; detritus was removed with wet gauze. The second pass was horizontal with coagulation setting at 30-50 without removing detritus. Zone C, feathering, was calculated at $50 \%$ of the sum of the first and second passes. Zone D was treated with fractional ablative resurfacing (ProFractional XC') with $11 \%$.

\section{Results}

Each of the authors analyzed the pre- and post-surgical photos after the final check-up, evaluating the results at good, fair or bad. The majority of patients were in the good category; none were categorized as bad (Figure 5). Patients' assessments were positive and none of them expressed dissatisfaction.
In one case, in spite of normal coagulation tests, a 67-year-old woman experienced profuse bleeding and the surgery had to be cancelled. From this experience, it was determined that all patients should take ascorbic acid prior to any invasive approach. In the case of a 53-year-old man, there was a remainder of fat at the upper nasal pocket that was extracted percutaneously.

\section{Discussion}

There is a consensus that blepharoplasty does not improve skin eyelids [15-17]. In order to overcome this, chemical peelings, fillers and laser resurfacing have been proposed [18-20]. The authors believe that laser is more beneficial than the others, although its purchase price and maintenance costs can be high. Er:YAG $2940 \mathrm{~nm}$ is near the peak of water absorption and is approximately 15 times more efficiently absorbed by water than $\mathrm{CO}_{2} 10,600 \mathrm{~nm}$. This feature allows the ablation of tissue with one fifth of the energy of the $\mathrm{CO}_{2}$ laser [21].

The average depth of epidermis plus dermis in the eyelids is $345 \mu \mathrm{m}$ [22]. This data plus observation and pinch tests of the skin determined the depth of laser ablation that was used as there was no ultrasound equipment to measure skin thickness. Hopefully, as laser resurfacing becomes more widespread, more portable and inexpensive equipment will become available and skin topography or optical coherence tomography will be possible as in the case of ablation of the cornea in lasik surgery [23].

Most of the literature on this topic is related to $\mathrm{CO}_{2}$ laser where they specify laser ablation in energy units instead of ablation depth [2426]. The authors have been unable to correlate $\mathrm{CO}_{2}$ with Er:YAG in regards to this important parameter. This led the authors to develop an algorithm in microns of ablation. ProFractional module applied to zone $\mathrm{D}$, lateral canthal, stretches the eyelid laterally, avoiding canthopexy (Figure 6). This algorithm enables a better customized treatment for

Table 1: Algorithm for Er: YAG laser in eyelid resurfacing.

\begin{tabular}{|l|c|l|}
\hline \multicolumn{1}{|c|}{ Zone } & \multicolumn{1}{|c|}{$\begin{array}{c}\text { First pass: Vertical } \\
\text { Coagulation } 0\end{array}$} & $\begin{array}{l}\text { Second pass: Horizontal } \\
\text { Coagulation 30-50 }(\mu \mathrm{m})\end{array}$ \\
\hline A: Upper Eyelids & Min: $70 \mu \mathrm{m}$-Max: $90 \mu \mathrm{m}$ & Min: $60 \mu \mathrm{m}$-Max: $80 \mu \mathrm{m}$ \\
\hline B: Lower Eyelids & Min: $80 \mu \mathrm{m}$-Max: $100 \mu \mathrm{m}$ & Min: $70 \mu \mathrm{m}$-Max: $90 \mu \mathrm{m}$ \\
\hline C: Feathering & \multicolumn{2}{|c|}{$1 / 2$ (First pass + second pass) } \\
\hline D: Lateral Canthal & \multicolumn{2}{|c|}{$150-250 \mu \mathrm{m} 11 \%$} \\
\hline
\end{tabular}
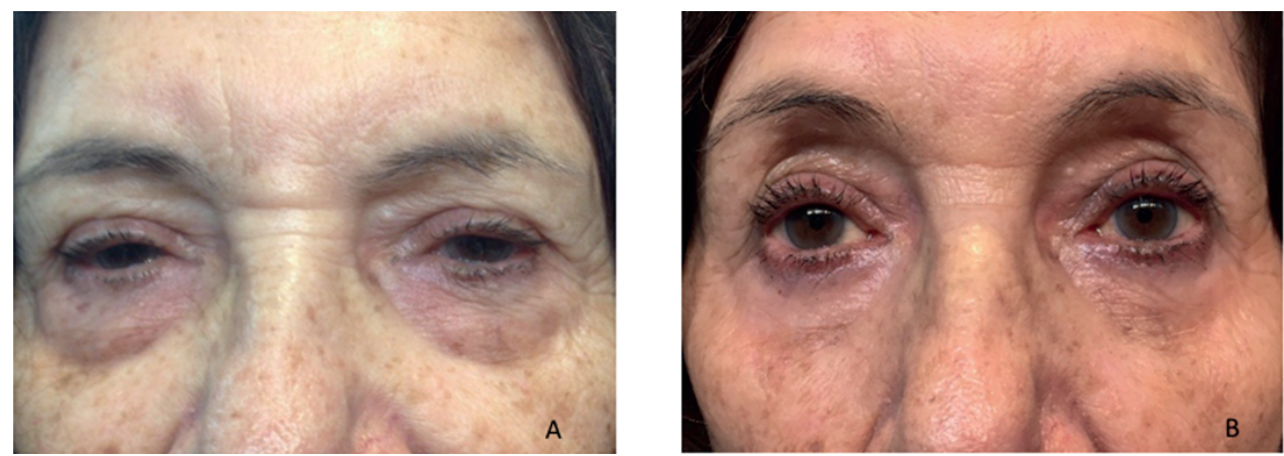

Figure 6: An 84-year-old woman A: preoperative. B: after 11 months without canthopexy or canthoplasty. Laser applied according to the algorithm. 
each patient. Careful patient selection for the procedure contributed to the excellent results and high degree of patient satisfaction.

The authors also propose the term "blepharolaser" as a shorter and more descriptive denomination for eyelid laser resurfacing. This term would be used when only laser is applied to eyelids without any invasive surgical procedure.

\section{Declaration of Conflicting Interests}

The author(s) declared no potential conflicts of interest with respect to the research, authorship, and/or publication of this article.

\section{Funding}

The author(s) received no financial support for the research, authorship, and/or publication of this article.

\section{Acknowledgements}

A special thanks to Ariel Kurtzig for his assistance in the creation of table 1 and for researching all references cited below.

\section{References}

1. Plastic Surgery Statistics Report (2018) American Society of Plastic Surgeons.

2. Blepharoplasty Market Size, Industry Analysis Report, Regional Outlook, Application Potential, Price Trends, Competitive Market Share \& Forecast, 2020-2026 Report ID: GMI4243.

3. The Aesthetic Society (2019) Aesthetic Plastic Surgery National Databank. Statistics 12.

4. Celsus AC, De Medicina (1989) English translation by Spencer WG. The Classics of Medicine Library. Birmingham, Alabama: Gryphon Ed Inc.

5. Miller CC (1907) Cosmetic surgery: The correction of featural imperfections. Chicago, IL.

6. Castañares S (1951) Blepharoplasty for herniated intraorbital fat: anatomical basis for a new approach. Plast Reconstr Surg 8: 46-65.

7. Kane MAC (2005) Treatment of Tear Trough Deformity and Lower Lid Bowing with Injectable Hyaluronic Acid. Aesth Plast Surg 29: 363367.

8. Baker SS, Muenzler WS, Small RG, Leonard JE (1984) Carbon dioxide laser blepharoplasty. Ophthalmology 91: 238-244.

9. Seckel BR, Kovanda CJ, Cetrulo CL Jr, Passmore AK, Meneses PG (2000) Laser blepharoplasty with transconjunctival orbicularis muscle/septum tightening and periocular skin resurfacing: A safe and advantageous technique. Plast Reconstr Surg 106: 1127-1141.

10. Fitzpatrick TB (1988) The validity and practicality of sun-reactive skin types I through VI. Arch Dermatol 124: 869-871.
11. Schwember J, Schwember G, Madrid L (2020) Secondary intention facial healing: crucial guidelines. Archives of Dermatology and skin care: 3.

12. Usatine RP, Pfenninger JL, Stulberg DL, Small R (2012) Skin care products. In: Dermatologic and Cosmetic Procedures in Office Practice. Elsevier Saunders: 291.

13. Zide MB, Swift R (1998) How to block and tackle the face. Plast Reconstr Surg 101: 840-851.

14. CC McCord CD, Codner MA, Nahai F (2008) Upper lid blepharoplasty. In McCord CD, Codner MA, eds. Eyelid \& Periorbital Surgery. St. Louis: Quality Medical Publishing, Inc, pp 193-222.

15. Hester TR, Codner MA, McCord CD, Nahai F, Giannopoulos A (2000) Evolution of technique of the direct transblepharoplasty approach for the correction of lower lid and midfacial aging: maximizing results and minimizing complications in a 5 -year experience. Plast Reconstr Surg 105: 393-406.

16. Holds JB (2010) Lower Eyelid Blepharoplasty: A procedure in evolution. Mo Med 107: 391-395.

17. Drolet BC, Sullivan PK (2014) Evidence-based medicine: blepharoplasty. Plast Reconstr Surg 133: 1195-1205.

18. Dailey RA, Gray JF, Rubin MG, Hildebrand PL, Swanson NA, et al. (1998) Histopathologic changes of the eyelid skin following tricholoroacetic acid chemical peel. Ophthalmic Plast Reconstr Surg 14: 9-12.

19. Lee S, Yen MT (2017) Nonsurgical rejuvenation of the eyelids with hyaluronic acid gel injections. Semin Plast Surg 31: 17-21.

20. Mannor GE, Phelps RG, Friedman AH, Meltzer M (1999) Eyelid healing after carbon dioxide laser skin resurfacing. Arch Ophthalmol 117: 913-916

21. Usatine RP, Pfenninger JL, Stulberg DL, Small R (2012) Skin resurfacing with ablative lasers. In: Dermatologic and Cosmetic Procedures in Office Practice. Elsevier Saunders: 351.

22. Richards RN, Uy M, Meharg G (1990) Temporary hair removal in patients with hirsutism: a clinical study. Cutis 45: 199-202.

23. Fujimoto JG, Pitris C, Boppart SA, Brezinski ME (2000) Optical coherence tomography: an emerging technology for biomedical imaging and optical biopsy. Neoplasia 2: 9-25.

24. Kotlus B (2010) Dual-depth fractional carbon dioxide laser resurfacing for periocular rhytidosis. Dermatol Surg 36: 623-628.

25. Khatri K, Sultan F, Anderson RR (1998) Patients views of comparison of Erbium: YAG and $\mathrm{CO}_{2}$ laser resurfacing. Lasers Surg Med 10: 76

26. Niamtu J (2015) Lower eyelid Synechia: a complication of periorbital $\mathrm{CO}_{2}$ laser resurfacing. Am J Cosmetic Surg 32: 137-143. 